Review

\title{
Vapor-based polymer coatings for potential biomedical applications
}

\author{
Joerg Lahann* \\ Departments of Chemical Engineering, Materials Science and Engineering, and Macromolecular Science and Engineering, University of \\ Michigan, Ann Arbor, MI 48109, USA
}

\begin{abstract}
Over the last decade, biology and biotechnology have witnessed an extraordinary development spanning genomics, proteomics, and metabolics. This progress was so rapid and definite that it not only changed the face of modern biology, but indeed altered the way day-to-day business is done in biology and related fields. This scientific advancement came with a need for concurrent technological advances. In this context, the ability to interface sophisticated devices with relevant biological microenvironments has emerged as a critical challenge. Already, novel biomaterials are on the horizon that promise to fulfill the rigid criteria of being both biocompatible under the conditions of a versatile range of biological applications and compatible with the increasing demands for miniaturization, integration, and throughput of future device architectures. As currently employed solvent-based polymer coatings are increasingly reaching their limits, a range of unconventional materials, such as vapor-based polymer coatings, are discussed as attractive alternatives. One of the main features of vapor-based polyreactions is their versatility in synthesizing both simple and complex polymers with relative ease and at generally low temperatures. The advantages of the chemical vapor deposition (CVD) technique also include control of the composition and architecture of the resulting materials, high accuracy, solvent-free environments, excellent adhesion, and the ability to accommodate custom-tailored surface modifications. For further illustration, selected examples of polymer-based surface engineering approaches using vapor-based polyreactions are discussed in this review. For instance, reactive coating technology uses CVD polymerization to deposit a wide range of chemically functionalized polymer coatings on various substrate materials. Its simplicity in providing chemically reactive groups and its applicability to three-dimensional geometries (e.g. for microfluidics) enables exact tailoring of surface properties and the preparation of biologically relevant microenvironments. CVD-based reactive coatings are compatible with soft lithographic processes allowing for patterning of proteins, DNA, cytokines, and mammalian cells.
\end{abstract}

(c) 2006 Society of Chemical Industry

Keywords: biomedical coatings; immobilization; surface engineering; biomaterials; surface analysis

\section{VAPOR-BASED SURFACE MODIFICATION METHODS}

Over the last few decades, a heterogeneous range of methods has been developed to deposit coatings from the vapor phase including laser-based processes, ${ }^{1}$ plasma $^{2-4}$ and hot filament ${ }^{5}$ polymerization, as well as chemical vapor deposition (CVD) polymerization. ${ }^{6}$ Similarly as heterogeneous as the spectrum of coating methods that have been employed, is the range of applications that have been met in biomedical settings. For instance, a research group at the University of Washington has used radio frequency plasma deposited tetraglyme to create surface coatings that resist protein adsorption and monocyte adhesion in vitro. ${ }^{7,8}$ Similarly, Gleason and co-workers used hot filament ${ }^{9,10}$ and plasma polymerization ${ }^{11,12}$ to create functional materials coatings. Moreover, vapor deposition has been shown to be applicable to an astonishingly wide range of polyreactions and polymer types. $\mathrm{Li}$ et al. reported the free radical polymerization of vinyl monomers resulting in polystyrene, polyacrylamide, or poly $(N$-isopropylacrylamide) using covalently attached initiators, ${ }^{13}$ while Yasutake et al. used a pre-adsorbed initiator to prepare methyl methacrylate/styrene block copolymers. ${ }^{14}$ The Frank group ${ }^{15-17}$ and, later, Wang and Chang ${ }^{18-21}$ reported the synthesis of polypeptides through the vapor-based polyaddition of $N$-carboxy anhydrides. Tsukagoshi et al. prepared thin polyamide films via alternate pulsed vapor-based polycondensation of terephthaloylchloride and 4, 4'-diaminodiphenyl ether, ${ }^{22}$ while $\mathrm{Fu}$ et al. reported on both the ring opening metathesis polymerization and the cationic polymerization of a range of different monomers. ${ }^{23}$ Vapor-based processes have also been used for the deposition of poly( $p$-phenylene vinylene), ${ }^{24-26}$ polydiacetylene, ${ }^{27}$

* Correspondence to: Joerg Lahann, Departments of Chemical Engineering, Materials Science and Engineering, and Macromolecular Science and Engineering, University of Michigan, Ann Arbor, MI 48109, USA

E-mail: lahann@unimich.edu

Contract/grant sponsor: NSF; contract/grant number: DMR-0449462

(Received 30 November 2005; revised version received 27 February 2006; accepted 14 March 2006)

Published online 26 June 2006; DOI: 10.1002/pi.2098 
poly(vinylidene fluoride), ${ }^{28}$ or polysiloxane coatings, to name only a few examples. ${ }^{29}$ It is obvious from these examples that CVD - already well established for the formation of inorganic layers - has received increasing attention for the deposition of polymer coatings. The main feature of CVD polymerization is its versatility in synthesizing both simple and complex polymers with relative ease and at generally low temperatures. Further advantages of CVD-based polymer deposition methods often include tight control over film composition, high coating fidelity, the use of solvent-free processes, as well as excellent adhesion properties. A major focus of this review is on vapor deposition of poly( $p$-xylylene $) \mathrm{s}^{30}$ via free radical polymerization and its applicability to biologically motivated surface engineering.

\section{CVD POLYMERIZATION OF [2.2]PARACYCLOPHANES: NON-REACTIVE POLYMER COATINGS}

In spite of the wide range of polyreactions that have been conducted from the vapor phase, the free radical polymerization of [2.2] paracyclophanes to yield poly( $p$-xylylene)s remains among the best established vapor-based polymerization technologies available today (Scheme 1). Non-functionalized poly(p-xylylene) coatings, originally developed by Gorham at Union Carbide, have been commercialized under the parylene brand, which includes parylene $\mathrm{N}$, parylene $\mathrm{C}$, and parylene $\mathrm{D}$. Although $\operatorname{poly}(p-$ xylylene)s can be prepared by various methods, including electrochemical deposition, ${ }^{31} \mathrm{CVD}$ polymerization of [2.2] paracyclophanes has been most widely used for the preparation of thin-film coatings (the socalled Gorham process). ${ }^{32}$ The structural situation in [2.2] paracyclophanes enables the thermal activation of the ring structure by vacuum pyrolysis; ideally without compromising the chemical backbone structure or side groups. The CVD polymerization of [2.2]paracyclophanes tracing back to the pioneering work of Gorham $^{32}$ has since resulted in a wide range of applications, such as the use in stents, ${ }^{33}$ cardic pacemakers ${ }^{34}$ and defibrillators, ${ }^{35}$ neuronal probes, ${ }^{36}$ orthodentic devices, ${ }^{37}$ or for BioMEMS applications. ${ }^{38,39}$ In a very interesting extension of these technological applications, Zeng et al. demonstrated the use of $\operatorname{poly}(p$-xylylene) coatings to modulate release kinetics

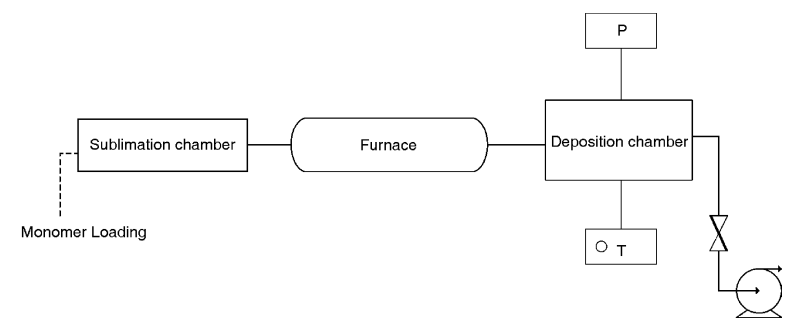

Scheme 1. Flow diagram of the Gorham process used for CVD polymerization. [2.2]Paracyclophanes are sublimed (1), transported into the pyrolysis zone (2), and deposited (3). of a drug incorporated into an underlying porous structure. ${ }^{40}$

Although commercially available non-functionalized parylene coatings have been used in the biomedical community for a range of applications, they still lack anchor groups for further modification and therefore fail as effective carriers for biomolecules. For this reason, several approaches have been recently developed to modify the surface properties of $\operatorname{poly}(p-$ xylylene) coatings, such as plasma etching ${ }^{41,42}$ or wet chemical modification via sulfonation, aminomethylation, or amidomethylation. ${ }^{43}$ Given the interest in surface-modified poly( $p$-xylylene)s, there is a clear need for intrinsically reactive vapor-deposited polymer coatings.

\section{CVD POLYMERIZATION OF SUBSTITUTED [2.2]PARACYCLOPHANES: REACTIVE POLYMER COATINGS}

In recent years there has been a number of attempts to expand the Gorham process to a wider range of custom-tailored poly( $p$-xylylene)s, such as poly(octafluoro- $p$-xylylene).$^{44}$ Although these coatings still do not have reactive functional groups for further surface modification, they may be of interest due to their outstanding optical properties. Moreover, a broad range of functionalized poly( $p$-xylylene)s has been prepared that have functional groups with sufficient reactivity to act as anchors for further surface engineering (Scheme 2).$^{45}$ These polymers often show all the advantages of their commercial siblings, but, in addition, provide a controlled platform for further surface modifications. ${ }^{46,47}$ In essence, this technology represents a one-step coating procedure to generate functionalized surfaces on a wide range of substrate materials and geometries ${ }^{48}$ - without requiring posttreatment once the films are deposited. ${ }^{49}$

Although $\quad \alpha, \alpha^{\prime}$-dihydroxy- $p$-xylylenes, ${ }^{50,51} \quad \alpha, \alpha^{\prime}$ dibromo- $p$-xylylenes, ${ }^{52} \alpha$-chloro- $p$-xylylenes, ${ }^{53}$ and $\alpha, \alpha^{\prime}$-diacetoxy- $p$-xylylenes ${ }^{54}$ provide potential candidates for functionalized poly( $p$-xylylene)s as they all have been shown to undergo CVD polymerization, substituted [2.2] paracyclophanes have been the preferred precursors for CVD polymerization - at least in our hands. ${ }^{55}$ Scheme 2 summarizes the synthesis of [2.2] paracyclophanes with various functional groups. When synthesizing mono- or disubstituted [2.2]paracyclophanes, the entry step is often a Friedel-Crafts acylization of the commercially available [2.2] paracyclophane. The resulting ketones can be used as they are, or modified by hydrolysis to yield 4-carboxy[2.2]paracyclophane and its derivatives. Other interesting polymers for biomedical applications include amino-substituted $\operatorname{poly}(p-$ xylylene)s. However, their preparation by CVD had been limited by the lack of facile and effective syntheses of amino-functionalized [2.2] paracyclophanes. 4-Amino[2.2]paracyclophane has been synthesized using a multistep approach via [2.2] paracyclophane 


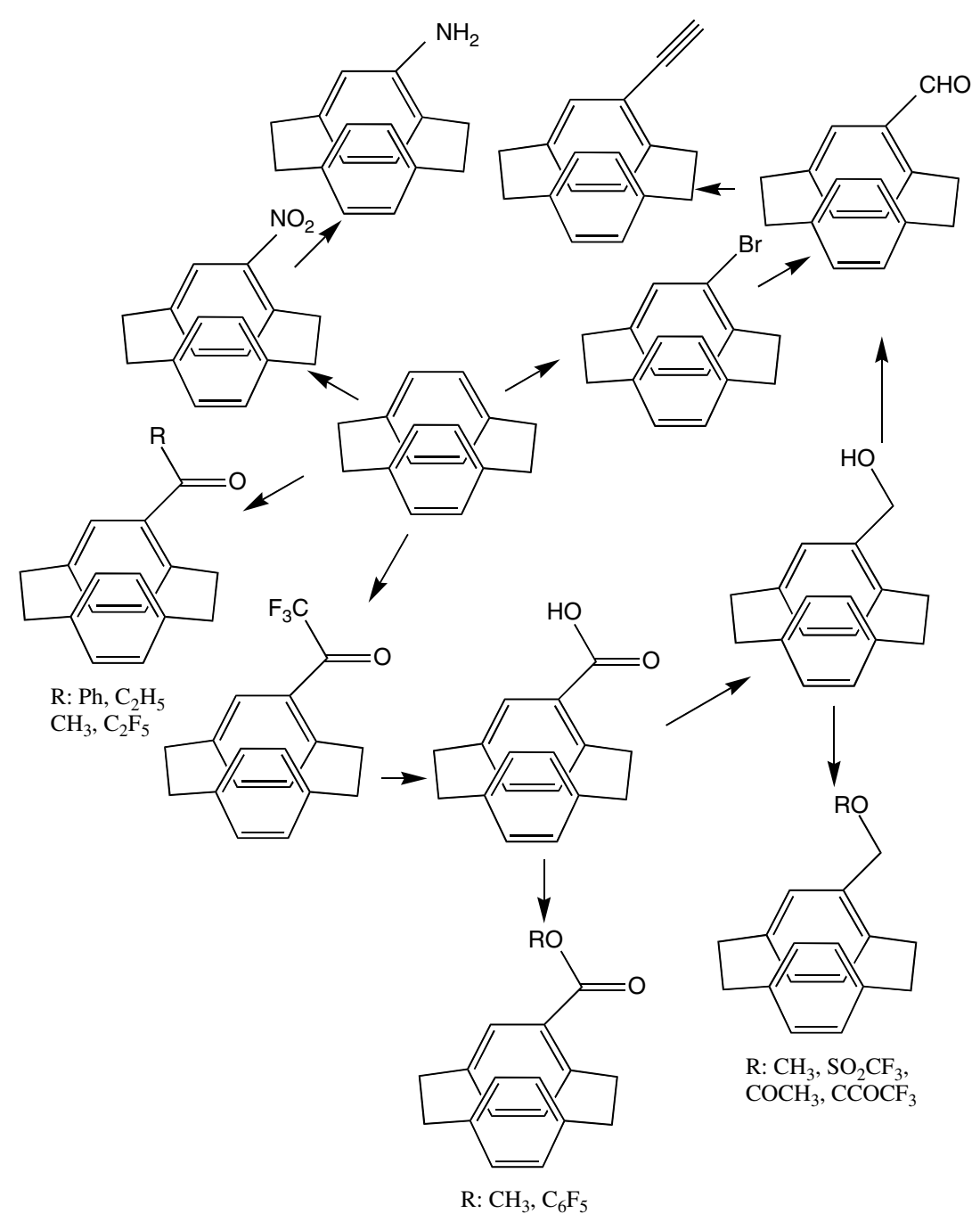

Scheme 2. CVD polymerization of substituted [2.2]paracyclophanes to yield a wide range of different poly(p-xylylene)s.

carboxylic as a key intermediate. ${ }^{56}$ Alternatively, treatment of [2.2] paracyclophane with nitronium ions, ${ }^{57}$ which exhibit high nitration power even at low temperatures, will yield 4-nitro[2.2]paracyclophane. The latter can be reduced to the corresponding amine. ${ }^{58}$ Alternatively, [2.2] paracyclophane can also be converted to the corresponding ethinyl derivative in a two-step reaction. ${ }^{59}$ Higher substituted [2.2]paracyclophanes, such as poly( $p$-xylylene) anhydride, are also suitable for CVD polymerization, but their synthesis is often more involved. In this case, 4,5,12,13tetrakis(methyloxycarbonyl) [2.2]paracyclophane is the key intermediate, which can be synthesized by Diels-Alder reaction of acetylenedicarboxylic acid dimethyl ester with hexatetraene. ${ }^{49}$ The hexatetraene is accessible by conversion of propargylic bromide with the Grignard compound allenylic magnesium bromide (Scheme 3). Dehydratization of 4,5,12,13tetrakis(methyloxycarbonyl) [2.2]paracyclophane with concentrated sulfuric acid resulted in [2.2] paracyclophane-4,5,12,13-tetracarboxylic acid dianhydride. [2.2] Paracyclophane-4,5,12,13-tetracarboxylic $\gamma$-butyryl lactone can be synthesized from the anhydride by cautious reduction with sodium borohydride.
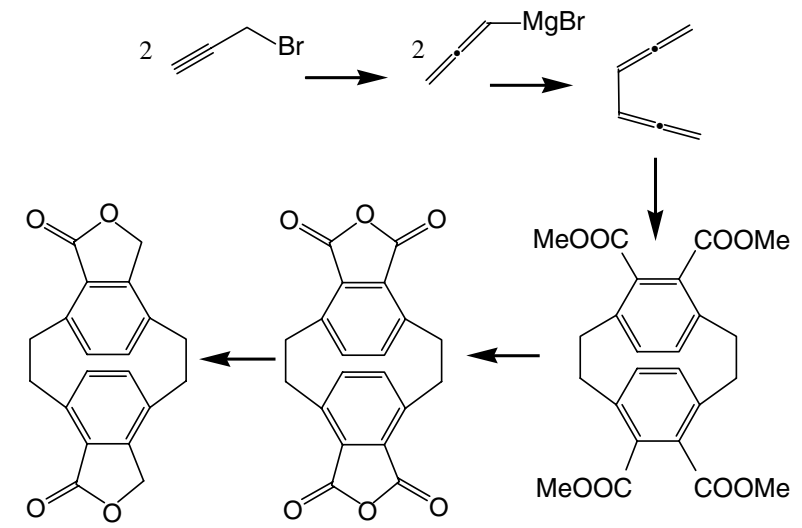

Scheme 3. Synthesis of mono-substituted [2.2]paracyclophanes as versatile precursors for CVD polymerization.

Once the substituted [2.2] paracyclophanes are synthesized, the subsequent CVD polymerization is a room temperature deposition process, which does not involve catalysts, solvents, or initiators. In the CVD process, the starting material, a substituted [2.2]paracyclophane, is sublimed and subsequently transferred into the pyrolysis zone. The [2.2] paracyclophanes comprise dimers, which can be 
symmetric or asymmetric, resulting in polymers or copolymers, respectively. Polymerization parameters must be selected to ensure cleavage of the $\mathrm{C}-\mathrm{C}$ single bonds resulting in the corresponding quinodimethanes. Subsequently, the monomer is transferred to a cooler deposition chamber, typically at or below room temperature, where spontaneous polymerization occurs. CVD polymerization of [2.2]paracyclophanes requires simultaneous control of multiple polymerization parameters. For most of the [2.2]paracyclophanes studied so far, we identified parameter sets, which can be used to create high-quality polymer films. A reaction system used for CVD polymerization is shown in Fig. 1 and essentially consists of a sublimation zone, a pyrolysis zone, and a deposition zone. The CVD installation must provide flexible control of polymerization parameters, as well as monitoring capability to record critical polymerization parameters. We use a custom-designed CVD polymerization for this purpose (Fig. 1). ${ }^{60} \mathrm{CVD}$ polymerization requires base pressures of around $5 \times 10^{-5}$ bar and working pressures (i.e. the pressure during polymerization) of about 0.05 to 0.6 mbar depending on the choice of [2.2] paracyclophane. The butterfly valve is located at the downstream part of the equipment, while the carrier gas inlet and flow control are both placed upstream. This allows one to control the working pressure within a flexible range of gas flows and also prevents sudden pressure fluctuations due to sublimation of the precursor. The mechanical pump easily accommodates working pressures below 0.08 mbar at a mass flow of $10 \mathrm{sccm}$ and 0.2 mbar at a mass flow of $20 \mathrm{sccm}$. Well-defined and usually chemically robust polymer films can be prepared under these conditions (Scheme 4). The adhesion of the CVD coatings can be assessed using a simple peel test. For instance, poly(4-formyl- $p$-xylylene-co- $p$-xylylene) was analyzed by pressing scotch tape onto the polymer coating and then peeling it off. Subsequent visual examination showed the intactness of the film and infrared spectral analysis confirmed the presence of the film (Fig. 2).

\section{BIOACTIVE SURFACES BASED ON REACTIVE COATINGS}

Reactive CVD coatings offer a wide range of chemical signatures and can be designed to support immobilization of a variety of different biomolecules including proteins $^{61}$ and sugars. $^{62}$ In a typical surface engineering pathway, CVD polymerization is used to create anchor groups on the surface of the substrate. In a consecutive step, the protein is brought into contact with the reactive CVD coating and spontaneously tethers to the surface via covalent bond formation. In some cases, the orientation of the protein is highly critical and an unfavorable orientation may result in loss of biological activity of the protein. In a series of experiments, we immobilized r-hirudin, the strongest known thrombin inhibitor, to the surface of a prospective biomaterial. ${ }^{63}$ A typical approach to immobilize proteins is through their primary amino groups, which can be reacted with activated groups on a surface. In case of r-hirudin, the $N$-terminal amino acid residues were found to be in a position essential to its thrombin activity. ${ }^{64,65}$ When pursuing this approach, the following dilemma arose: while the $N$-terminal amino group has a superior chemical reactivity compared to the remaining three lysine $\varepsilon$-amino groups, ${ }^{66}$ its free availability is critical for r-hirudin's thrombin inhibition capacity. Therefore, an indirect immobilization strategy was chosen using an $\mathrm{N}$-terminally protected $\mathrm{r}$-hirudin derivative for immobilization (Scheme 5). Deprotection of the surface bound r-hirudin derivatives and intensive

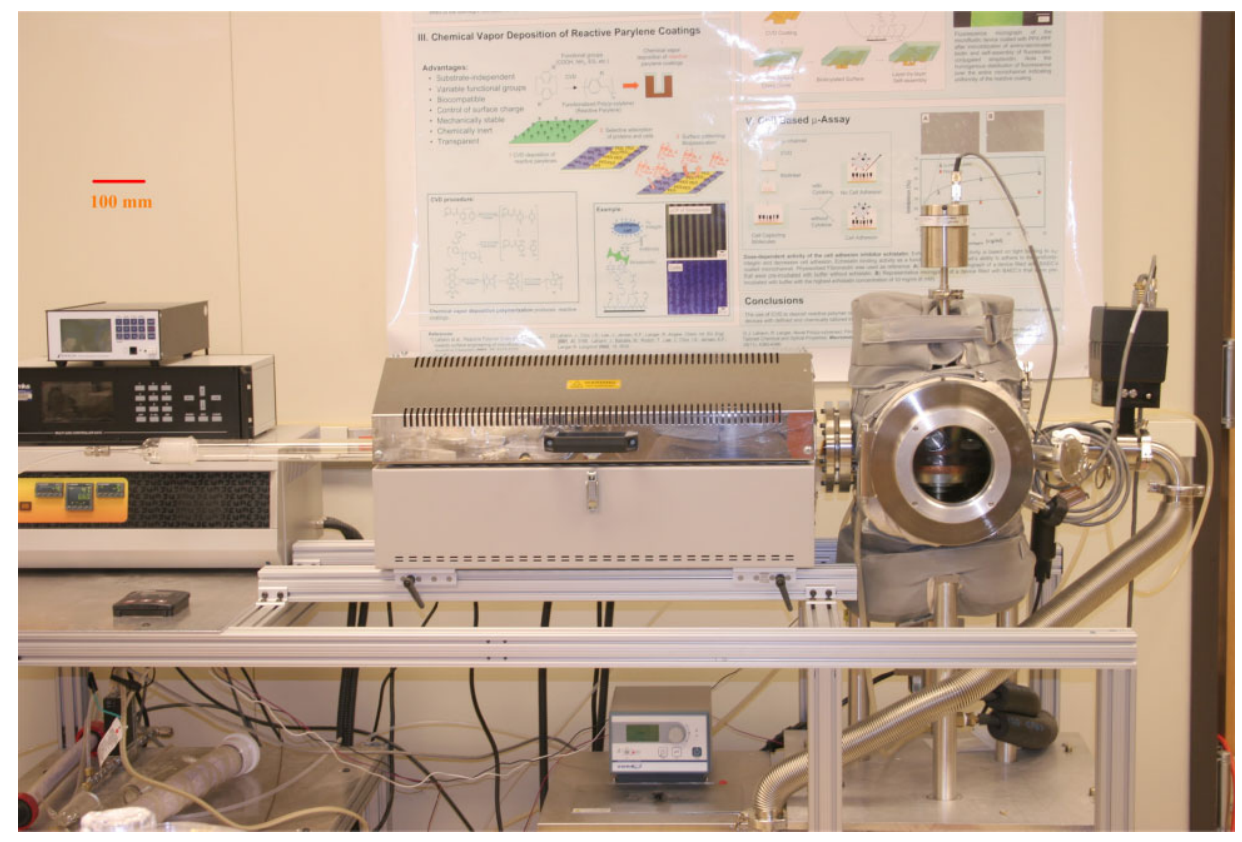

Figure 1. Digital image of a CVD installation that is used to prepare reactive coatings based on functionalized poly( $p$-xylylene)s. 


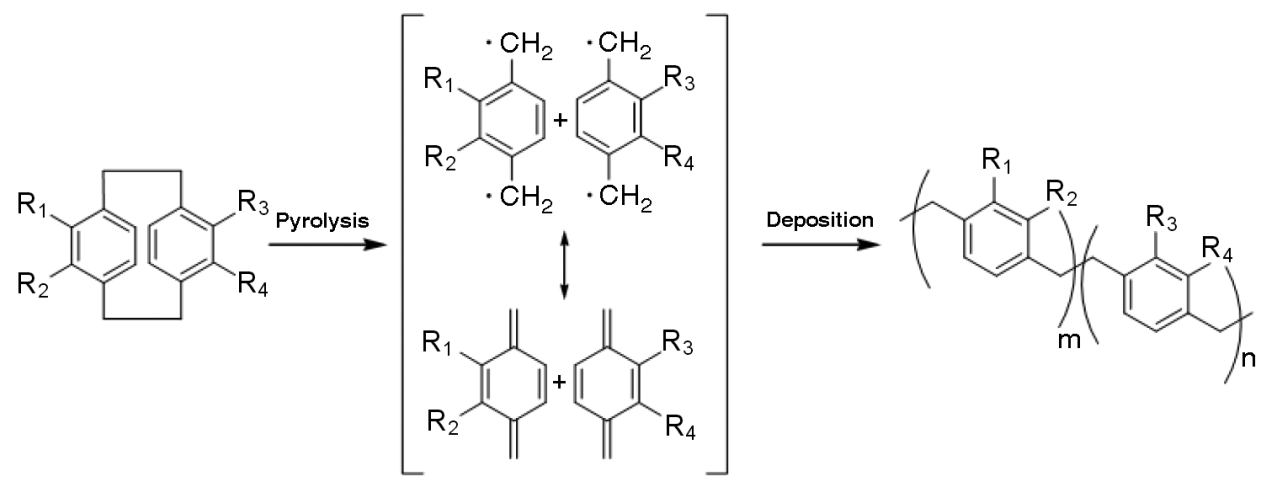

$\begin{array}{llll}\mathrm{R}_{1} & \mathrm{R}_{2} & \mathrm{R}_{3} & \mathrm{R}_{4} \\ \mathrm{CHO} & \mathrm{H} & \mathrm{H} & \mathrm{H} \\ \mathrm{COCH}_{3} & \mathrm{H} & \mathrm{H} & \mathrm{H} \\ \mathrm{COC}_{2} \mathrm{H}_{5} & \mathrm{H} & \mathrm{H} & \mathrm{H} \\ \mathrm{COCF}_{3} & \mathrm{H} & \mathrm{H} & \mathrm{H} \\ \mathrm{COC}_{2} \mathrm{~F}_{5} & \mathrm{H} & \mathrm{H} & \mathrm{H} \\ \mathrm{COPh} & \mathrm{H} & \mathrm{H} & \mathrm{H} \\ \mathrm{COPh} & \mathrm{H} & \mathrm{COPh} & \mathrm{H} \\ \mathrm{NH}_{2} & \mathrm{H} & \mathrm{H} & \mathrm{H} \\ \mathrm{NH}_{2} & \mathrm{H} & \mathrm{NH} & \mathrm{H} \\ \mathrm{CH}_{2} \mathrm{NH} & \mathrm{H} & \mathrm{H} & \mathrm{H} \\ \mathrm{C} \equiv \mathrm{CH} & \mathrm{H} & \mathrm{H} & \mathrm{H}\end{array}$

$\begin{array}{llll}\mathrm{R}_{1} & \mathrm{R}_{2} & \mathrm{R}_{3} & \mathrm{R} \\ \mathrm{CH}_{2} \mathrm{OH} & \mathrm{H} & \mathrm{H} & \mathrm{H} \\ \mathrm{CH}_{2} \mathrm{OCH}_{3} & \mathrm{H} & \mathrm{H} & \mathrm{H} \\ \mathrm{CH}_{2} \mathrm{OCOCH}_{3} & \mathrm{H} & \mathrm{H} & \mathrm{H} \\ \mathrm{COOCH}_{3} & \mathrm{H} & \mathrm{H} & \mathrm{H} \\ \mathrm{COOCH}_{3} & \mathrm{COOCH}_{3} & \mathrm{COOCH} & \mathrm{COOCH} \\ \mathrm{CH}_{2} \mathrm{OCOPpf}_{3} & \mathrm{H} & \mathrm{H} & \mathrm{H} \\ \mathrm{CH}_{2} \mathrm{OCOCF}_{3} & \mathrm{H} & \mathrm{H} & \mathrm{H} \\ \mathrm{Cl} & \mathrm{H} & \mathrm{H} & \mathrm{H} \\ \mathrm{Br} & \mathrm{H} & \mathrm{H} & \mathrm{H} \\ \mathrm{H} & \mathrm{H} & \mathrm{H} & \mathrm{H}\end{array}$

Scheme 4. Synthesis of substituted [2.2]paracyclophanes.

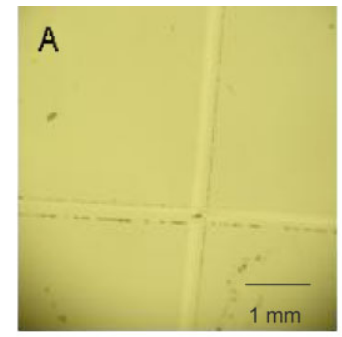

Before

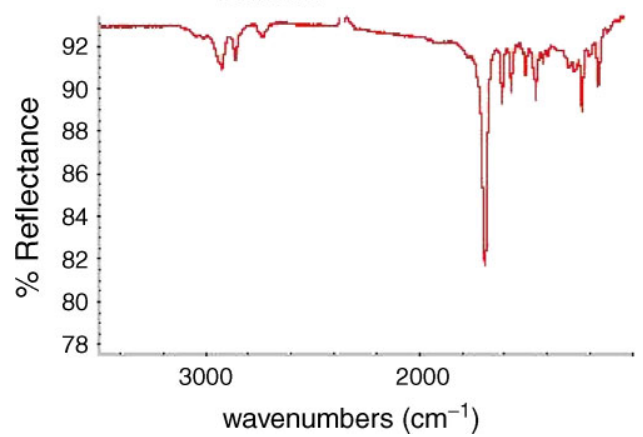

B

Adhesion test

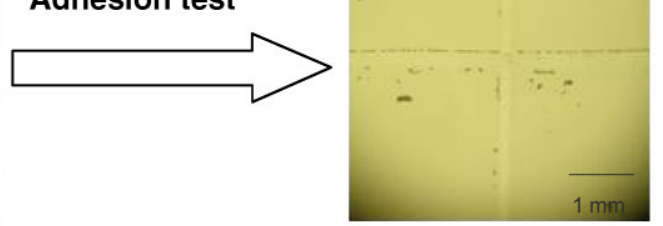

After

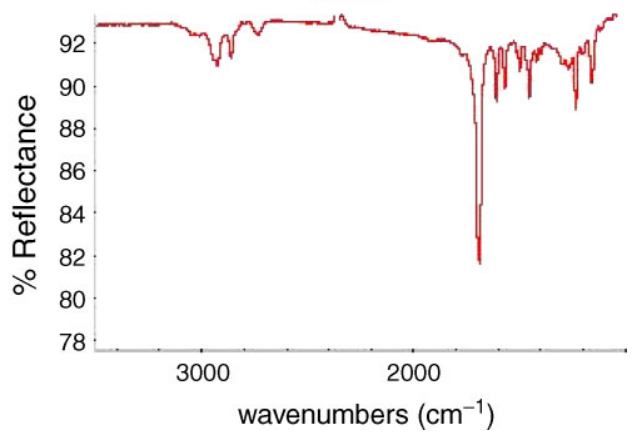

Figure 2. Adhesion test routinely used in the author's laboratory for reactive coatings; shown for poly(4-formyl-p-xylylene-co-p-xylylene). ${ }^{62}$

rinsing with sodium dodecyl sulfate-containing buffer delivers surfaces with covalently bound active $r-$ hirudin. Bivalent hexamethylene diisocyanate linkers were used for immobilization. In the case of $\operatorname{poly}(p-$ xylylene-2,3-dicarboxylic acid anhydride), however, the reactivity of the anhydride group was sufficient for a direct linkage of (MSC)-r-hirudin without further introduction of spacer moieties. ${ }^{60}$ The activity of surface-bound r-hirudin towards thrombin was determined using a thrombin time assay. Surfaces prepared by covalent linkage of r-hirudin show strongly enhanced prolongation of blood clotting due to inactivation of thrombin by surface-bound r-hirudin. These concepts are not only applicable to r-hirudin, but may be extended to other proteins of similar structure or function. After all, the choice of a specific immobilization strategy needs to be decided on a case-to-case basis. 
Although less common, the aldehyde functionality exemplifies another candidate group useful for surface modification, because of its high specificity towards functional groups such as hydrazide, hydroxylamino, and thiosemicarbazide groups. ${ }^{67}$ Several strategies have been reported to generate aldehyde groups on a variety of surfaces, such as glass, silicon, and metal surfaces. These processes involve either multistep chemistries or plasma polymerization of aldehydecontaining monomers. ${ }^{68-71}$ However, a substrateindependent procedure, such as CVD polymerization, is highly attractive for the preparation of aldehydefunctionalized surfaces.

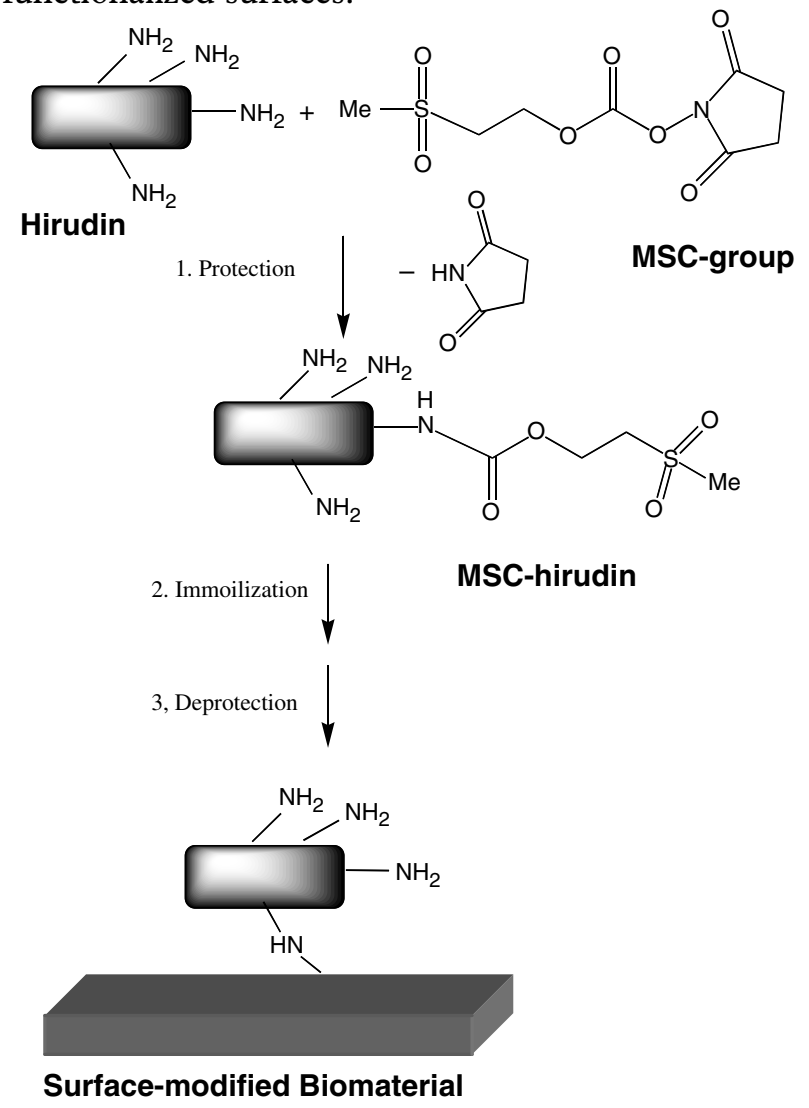

Scheme 5. Immobilization of r-hirudin following an indirect immobilization strategy consisting of (1) selective protection, (2) immobilization, and (3) deprotection.
In a recent communication, we reported the CVD polymerization of 4-formyl[2,2]paracyclophane to yield an aldehyde-functionalized poly ( $p$-xylylene), poly(4-formyl- $p$-xylylene-co- $p$-xylylene), which is suitable for the immobilization of polysaccharides (Scheme 6) ${ }^{62}$ The precursor 4-formyl[2,2] paracyclophane can be synthesized via a two-step synthesis from [2.2]paracyclophane. The resulting CVD coating was insoluble in aqueous solutions as well as in a variety of standard organic solvents such as ethanol, acetone, methanol, dichloromethane, chloroform, dimethylformamide, and toluene. The insolubility in organic solvents distinguishes the polymer films from starting material and suggests that high-molecular weight polymers are formed under the conditions of CVD polymerization.

The availability and reactivity of the aldehyde groups on poly(4-formyl- $p$-xylylene-co- $p$-xylylene) was studied using hydrazone formation. ${ }^{62}$ Using microcontact printing $(\mu \mathrm{CP})$, the condensation reaction between the aldehyde groups on the surface and a biotinyl hydrazide was performed (Fig. 3). After immobilization, homogeneous and reproducible patterns of sugar/lectin pairs were observed on the reactive coating, thus showing that the aldehyde groups on the surface are reactive and can be used as anchoring sites.

We further fabricated protein-resistant surfaces based on vapor deposition of a photodefinable coating, poly(4-benzoyl- $p$-xylylene-co- $p$-xylylene), on the luminal surface of a microfluidic device followed by a photopatterning step (Fig. 4).$^{72}$ Due to its structural analogy to benzophenone, this photoreactive coating can be activated at wavelengths of about $340 \mathrm{~nm}$. The temporarily generated free radicals at the carbonyl position spontaneously react with adjunct molecules, mainly via $\mathrm{C}-\mathrm{H}$ abstraction, and are crosslinked to the surface. ${ }^{73}$ Based on this method, spatially controlled confinement of non-fouling molecules, specifically poly(ethylene oxide)s (PEOs), can be achieved. ${ }^{74}$ Prior to photopatterning, the reactive coating is exposed to an aqueous solution of PEO. A photomask is then brought in close proximity to the surface and the CVD

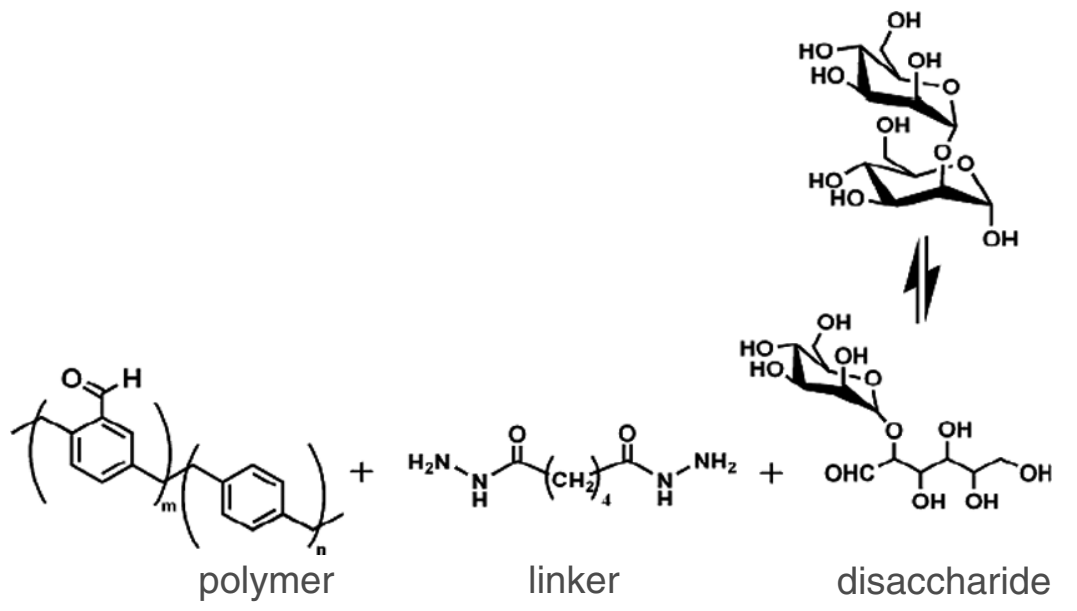

Scheme 6. Immobilization of a disaccharide to an aldehyde-reactive CVD coating. 

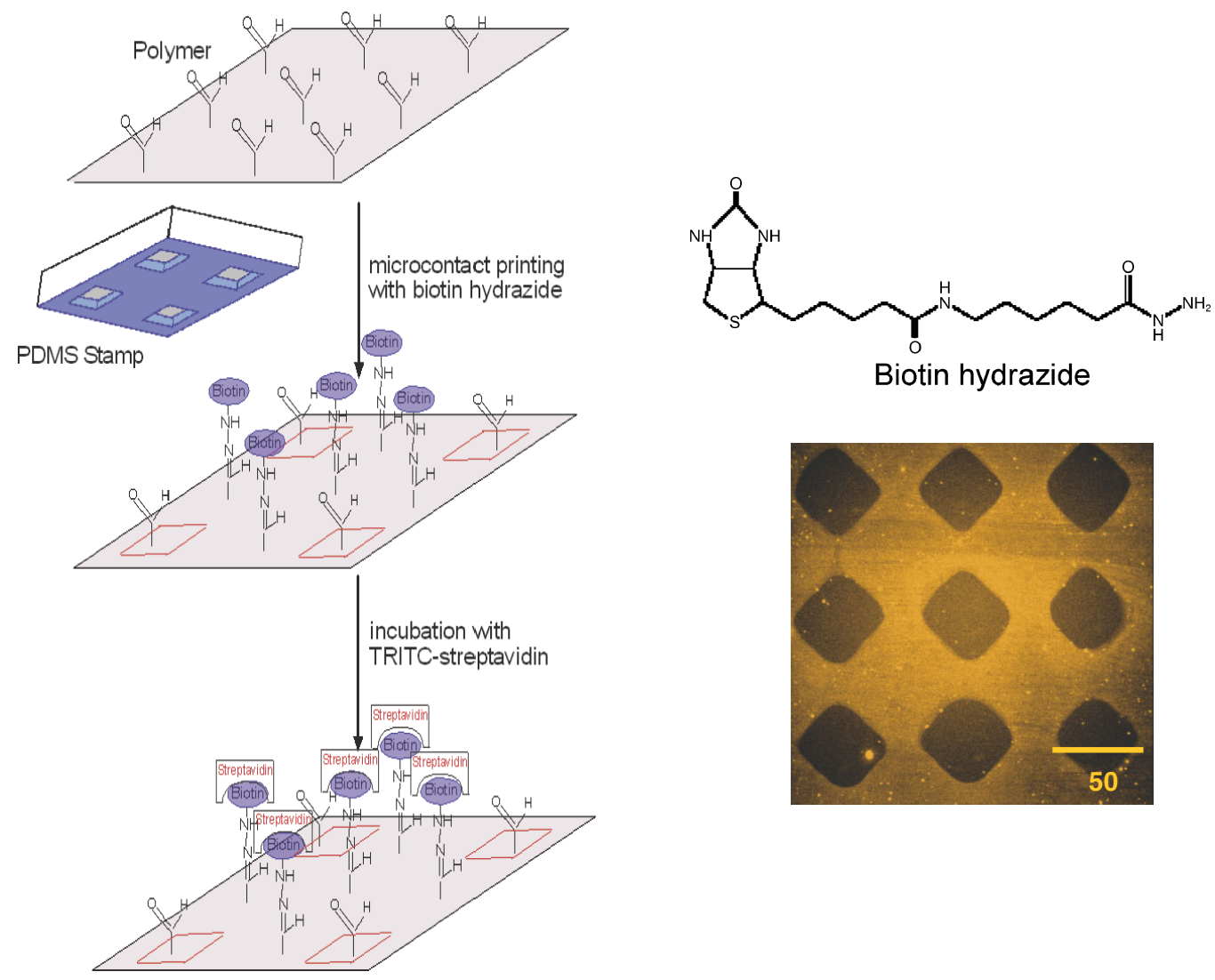

Figure 3. Fluorescence image of TRITC-labeled streptavidin conjugated to biotin-based ligands, which were patterned onto the reactive coating using $\mu \mathrm{CP} .62$

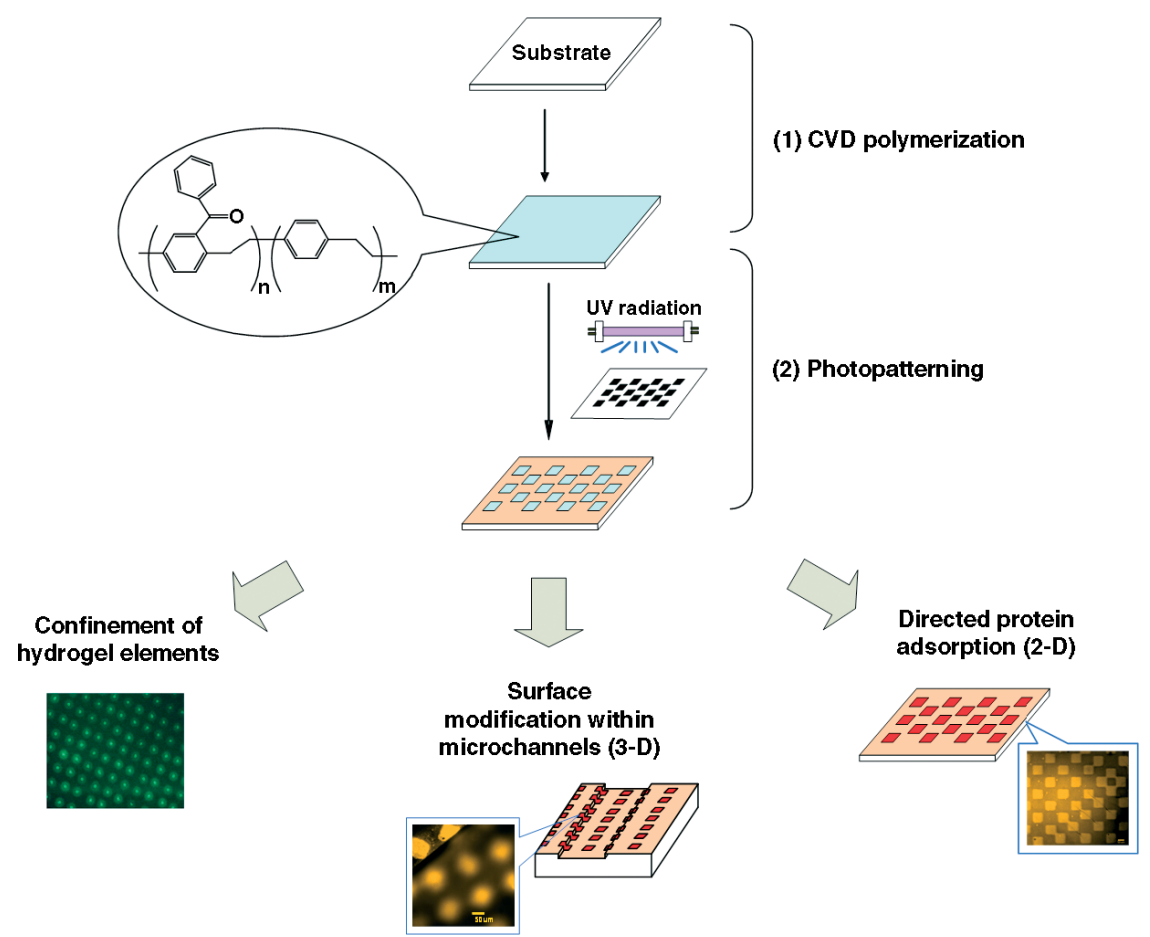

Figure 4. Schematic representation of the photopatterning method based on CVD polymerization of a photoreactive coating followed by subsequent photolithography. ${ }^{72}$

coating is illuminated through the mask. The CVD film essentially acts as a reactive photoresist and binds the PEO molecules only in those areas exposed to the light. ${ }^{75}$ To verify the bioinert properties of the surfaces after covalent tethering of the PEO, we incubated the entire sample surface with fluorescence-labeled model proteins including fibrinogen and albumin. Both proteins selectively adsorbed only to areas that 
corresponded to non-modified surfaces, while areas that were modified with PEO showed very low levels of protein adsorption, as concluded from the fluorescence micrographs. The patterning quality was limited by the spatial resolution of the photomask and the distance of the photomask from the surface, i.e. the depth of the microchannel.

To explore a biologically relevant system with dimensions on the micrometer scale, interactions of patterned surfaces with endothelial cells were studied. ${ }^{76}$ In this study, we essentially established a platform that allows spatially defined self-assembly of antibodies that bind to features expressed on a cell surface. This platform was used to guide cells to defined locations on the substrate. It is well known that cell adhesion is a specific process that involves interactions between cell adhesion mediators and cell surface receptors. For spatial control of cell attachment, a sequence of steps was conducted: (1) application of the reactive coating, (2) $\mu \mathrm{CP}$ of amino-derived biotin ligands, and (3) layer-by-layer self-assembly on patterned surfaces. A basic scheme is shown in Fig. 5. Since the first step involves the coating of the surface, the procedure is independent of the substrate material. Potential biological applications are discussed in the following section.

\section{POTENTIAL APPLICATIONS RELATED TO BIO-ANALYTICAL SYSTEMS}

Miniaturized cell assays are of interest in the evaluation of pharmacologically active molecules including molecules that affect cell proliferation and adhesion. In this context, the ability to create cell patterns may be useful for advanced biological applications. For instance, we used CVD-based surface engineering methods to confine endothelial cells on the luminal surface of a microchannel and studied the in vitro activity of echistatin, a potent disintegrin and cell adhesion inhibitor. For this purpose, immobilization of an antibody that specifically captures $\alpha_{5}$-integrin to a biotin-modified, CVD-coated microdevice was used to confine endothelial cells inside the microfluidic system. Suspensions of endothelial cells containing various concentrations of echistatin were then perfused into the microchannels presenting $\alpha_{5}$-integrincapturing antibodies. This setup allowed for monitoring the dose-dependent activity of echistatin by determining the number of attached endothelial cells (Fig. 6). For higher concentrations of the disintegrin, the inhibition of cell adhesion was higher on the antibody-coated surfaces than on the reference surfaces, revealing a higher selectivity with which cells bind to the antibody-coated surfaces (Fig. 7). These results provide the first evidence of the applicability of the systems described above as cell-based biosensors for chemical or biological agents ${ }^{77}$ or microfluidic assays. ${ }^{76,78}$

\section{CONCLUSIONS}

CVD polymerization of functionalized [2.2]paracyclophanes establishes a general but simple protocol for the preparation of polymer films. Applicability of the reactive coating to various substrates, such as polymers, metals, or composites, ${ }^{58}$ generates a fairly universal platform without relying on broad chemical alteration of the bulk material. The reactive coatings have anchor groups with reactivity patterns that enable selective binding of biomolecules using aqueous

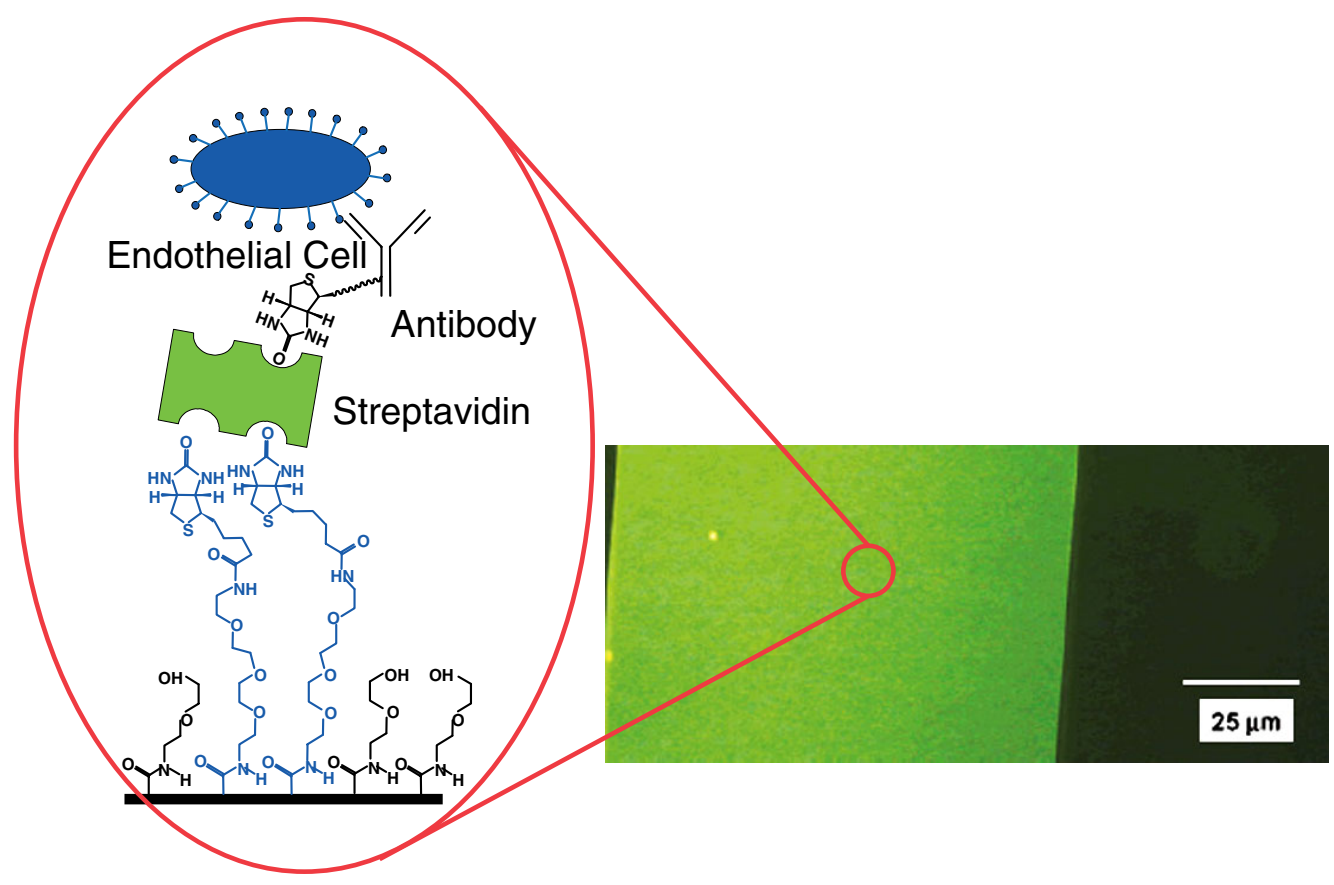

Figure 5. Schematic representation of the surface modification that lead to a microdevice with a biologically active surface. The device is first modified with a reactive coating, which is then used to bind biotin ligands and streptavidin. A biotin-labeled antibody is then bound to the modified PDMS surface and used to study cell surface receptor activity. Corner: fluorescence-labeled streptavidin bound in the microchannel. ${ }^{76}$ 


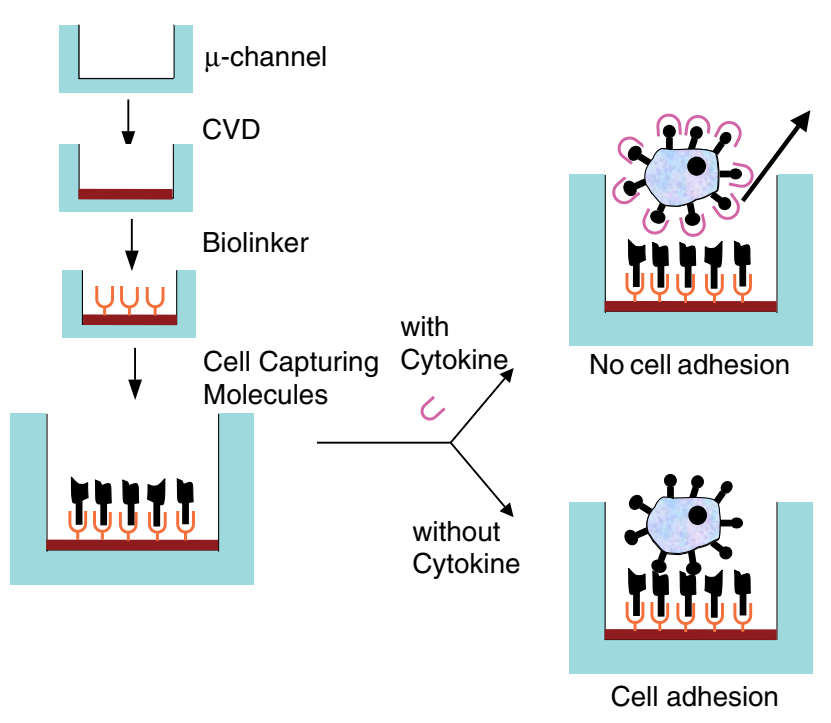

Figure 6. Schematic representation of the cell assay format used to study cell adhesion events in response to cell adhesion inhibitor candidates (e.g. echistatin). ${ }^{76}$

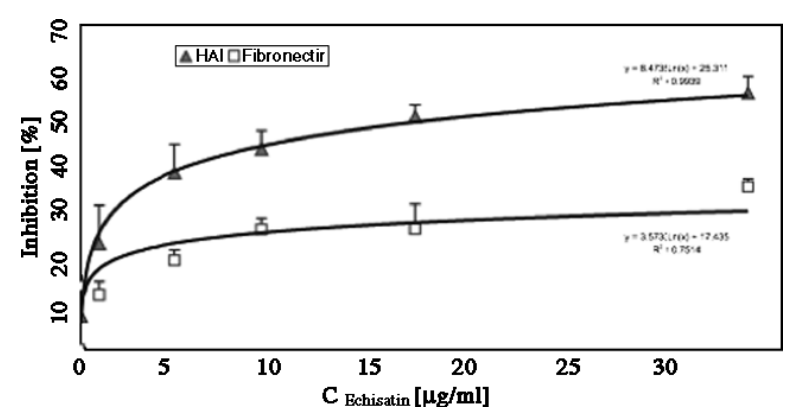

Figure 7. Dose-dependent activity of the cell adhesion inhibitor echistatin. Echistatin's biological activity is based on tight binding to $\alpha_{5}$-integrin and decreases cell adhesion. The binding activity of echistatin was studied as a function of the inhibition of a cell's ability to adhere to the antibody-coated microchannel. Physisorbed fibronectin was used as reference. Values are reported as the mean \pm standard deviation (SD) and statistical analysis was performed by single-factor ANOVA for repeated measures followed by a paired t test. Values of $P<0.05$ (one-tailed analysis) were considered significant. ${ }^{76}$

chemistry. This eliminates contaminations and guarantees a biocompatible process being free of harmful solvents, initiators, or accelerators. Reactive polymer coatings can improve the interfacial biocompatibility of implant surfaces or can be compatible with complex biological features as they represent a designable interlayer; stable under the conditions of the bioassay. Aldehyde, anhydride, or active ester groups allow for immobilization of proteins; amino or carboxylic acid groups may be used to control surface charges and electro-osmotic flow; while alkyl and fluoroalkyl groups may provide hydrophobic interfaces for electrochromatographic applications. Another critical feature of reactive coatings with respect to biointerface engineering is their compatibility with microstructuring by means of $\mu \mathrm{CP}$ or photopatterning. The resulting patterned surfaces can then be used to control selfassembly of objects on the nano- and micrometer scales. CVD-based polymer coatings, and specifically functionalized poly ( $p$-xylylene)s, represent a fascinating family of materials with unique features in terms of synthesis, physical properties, and biomedical applications.

\section{ACKNOWLEDGEMENT}

The author gratefully acknowledges support from the NSF in the form of a CAREER grant (DMR0449462).

\section{REFERENCES}

1 Chrisey D, Pique A, McGill R, Horwitz J, Ringeisen B, Bubb DM, et al, Chem Rev 553 (2003).

2 Schiller S, Hu J, Jenkins AT, Timmons RB, Sanchez-Estrada FS and Knoll W, Chem Mater 14:235 (2002).

3 Calderon J and Timmons R, Macromolecules 31:3216 (1998).

4 Nichols MF, Biomed Sci Instrum 29:77 (1993).

5 Mao Y and Gleason K, Langmuir 20:2484 (2004).

6 Lahann J, Chem Eng Commun (in press).

7 Shen M, Pan Y, Wagner M, Hauch K, Castner D, Ratner B, et al, Langmuir 19:1692 (2003).

8 Shen M, Wagner M, Castner D, Ratner B and Horbett T, f Biomater Res Polym Ed 12:961 (2002).

9 Murthy S, Olsen B and Gleason K, J Appl Polym Sci 91:2176 (2004).

10 Murthy S and Gleason K, Macromolecules 35:1967 (2002).

$11 \mathrm{Wu}$ Q and Gleason K, F Vac Sci Technol A 21:388 (2003).

12 Wu Q and Gleason K, Plasmas Polym 8:31 (2003).

$13 \mathrm{Li} \mathrm{J}$, Chen X and Chang Y-C, Langmuir 21:9562 (2005).

14 Yasutake M, Hiki S, Andou Y and Nishida H, Macromolecules 36:5974 (2003).

15 Lee N and Frank C, Langmuir 19:1295 (2003).

16 Chang Y and Frank C, Langmuir 12:5824 (1996).

17 Chang Y and Frank C, Polym Prepr 38:945 (1997).

18 Wang Y and Chang YC, Langmuir 18:9859 (2002).

19 Wang Y and Chang YC, Macromolecules 36:6511 (2003).

20 Wang Y and Chang YC, Macromolecules 36:6503 (2003).

21 Wang Y and Chang YC, $\mathcal{f}$ Am Chem Soc 125:6376 (2003).

22 Tsukagoshi, Mizutani W, Tokumoto H, Miyamae T and Nozoye H, Surf Sci 514:48 (2002).

23 Fu D, Weng LT, Du B, Tsui OK and Xu B Adv Mater 14:339 (2002).

24 Kokane S, Patankar MP, Narasimhan KL and Periasamy N, Synth Met 132:235 (2003).

25 Vaeth KM and Jensen KF, Macromolecules 31:6789 (1998).

26 Vaeth KM and Jensen KF, Appl Phys Lett 71:2091 (1997).

27 Tatsuo K, Ishikawa K, Khoda T, Tokoura $\mathrm{Y}$ and Takeda K, Appl Phys Lett 51:1957 (1987).

28 Kubono A, Kitoh T, Kajikawa K, Umemoto S and Takezoe H, Jpn f Appl Phys 31:1195 (1992).

29 Shirai $M$, Kinoshita $H$, Sumino T, Miwa $\mathrm{T}$ and Tsunooka $M$, Chem Mater 5:98 (1993).

30 Klee D, Weiss $\mathrm{N}$ and Lahann J, Vapor-based polymerization of functionalized [2.2]paracyclophanes: a unique approach towards surface-engineered microenvironments, in Paracyclophanes, ed. by Hopf H. VCH, Weinheim (2004).

31 Ultley J, Gao Y, Gruber J and Lines R, f Mater Chem 5:1297 (1995).

32 Gorham WF, f Polym Sci A 4:3027 (1966).

33 Instructions for Use: Cypher Sirolimus-Eluting Coronary Stent on Raptor Over-the-Wire Delivery Systems. [Online]. Available: www.fda.gov/cdrh/pdf3/P020026c.pdf [31 May 2006].

34 Iguchi N, Kasanuki H, Matsuda N, Shoda M, Ohnishi S and Hosoda SP, Pacing Clin Electrophysiol 20:372 (1997).

35 Available: http://www.scscoatings.com/parylene_applications/ medical.cfm [31 May 2006].

36 Takeuchi S, Zeigler D, Yoshida Y, Mabuchi K and Suzuki T, Lab Chip 5:519 (2005). 
37 McKamey RP, Whitley JQ and Kusy RP, f Mater Sci 11:407 (2000).

38 Weisenberg BA and Mooradian DL, F Biomed Mater Res 60:283 (2002).

39 Ryu KS, Shaikh K, Goluch E, Fan Z and Liu C, Lab Chip 4:608 (2004).

40 Zeng J, Aigner A, Czubayko F, Kissel T, Wendorff JH and Greiner A, Biomacromolecules 6:1484 (2005).

41 Lahann J, Klee D, Thelen H, Bienert H, Vorwerk D and Höcker H, f Mater Sci: Mater Med 10:443 (1999).

42 Nowlin TE and Smith DE, f Appl Polym Sci 25:1619 (1980).

43 Herrera-Alonso $M$ and McCarthy TJ, Langmuir 20:9184 (2004).

44 Dolbier WR and Beach WF, f Fluorine Chem 122:97 (2003).

45 Lahann J, Choi IS, Lee J, Jensen K and Langer R, Angew Chem Int Ed 40:3166 (2001).

46 Suh K, Langer R and Lahann J, Adv Mater 16:1401 (2004).

47 Lahann J and Langer R, Macromol Rapid Commun 22:968 (2001).

48 Lahann J and Langer R, Macromolecules 35:4380 (2002).

49 Lahann J, Klee D and Höcker H, Macromol Rapid Commun 19:441 (1998).

50 Simon P, Mang S, Hasenhindl A, Gronski W and Greiner A, Macromolecules 31:8775 (1998).

51 Ganguli S, Agrawal H, Wang B, McDonald JF, Lu TM, Yang GR, et al, $\mathcal{F}$ Vac Sci Technol A 15:3138 (1997).

52 You L, Yang G, Lang C, Wu P, Moore J, McDonald J, et al, f Vac Sci Technol A 11:3047 (1993).

53 Ishaque M, Agarwal S and Greiner A, E-Polymers, art. 031 (2002)

54 Schmidt C, Stuempflen V, Wendorff J, Hasenhindl A, Gronski W, Ishaque $M$ and Greiner A, Acta Polym 49:232 (1998).

55 Lahann J, Balcells M, Rodon T, Lee J, Choi IS, Jensen KF and Langer R, Langmuir 18:3632 (2002).

56 Waters J, Sutter J, Meador M and Baldwin L, f Polym Sci A: Polym Chem 29:1917 (1991).
57 Olah G and Narang S, Synthesis 9:690 (1978).

58 Lahann J, Höcker H and Langer R, Angew Chem Int Ed 40:726 (2001).

59 Nandivada H, Chen HY and Lahann J, Angew Chem Int ED 45:3360 (2006).

60 Lahann J, Plüster W, Klee D and Höcker H, Biomaterials 22:817 (2001).

61 Lahann J, Plüster W, Gattner H-G, Klee D and Höcker H, f Mater Sci: Mater Med 12:807 (2001).

62 Nandivada H, Chen HY and Lahann J, Macromol Rapid Commun 26:1794 (2005).

63 Lahann J, Plüster W, Rodon T, Fabry M, Klee D, Gattner H-G and Höcker H, Macromol Biosci 2:82 (2002).

64 Chang JY, FEBS Lett 164:307 (1983).

65 Dodt J, Seemüller U, Müller HP and Chang JY, FEBS Lett 165:180 (1984).

66 Tulinsky A, Semin Thrombosis Haemostasis 22:117 (1996).

67 Hermanson GT, Bioconjugate Techniques, 1st edition. Academic Press, San Diego, CA (1996).

68 Christman KL and Maynard HD, Langmuir 21:8389 (2005).

69 Gong X, Dai L, Griesser HJ and Mau AWH, 7 Polym Sci B: Polym Phys 38:2323 (2000).

70 Yeo WS and Mrksich M, Adv Mater 16:1352 (2004).

71 Feng J, Gao CY, Wang B and Shen JC, Colloids Surf B: Biointerf 3-4:177 (2004).

72 Smith JP and Hinson-Smith V, Anal Chem 77:412A (2005).

73 Shen WW, Boxer SG, Knoll W and Frank CW, Biomacromolecules 2:70 (2001).

74 Chen HY and Lahann J, Anal Chem 77:6909 (2005).

75 Suh K, Langer R and Lahann J, Adv Mater 16:1401 (2004).

76 Lahann J, Balcells M, Lu H, Radon T, Jensen KF and Langer R, Anal Chem 75:2117 (2003).

77 Takayama S, Ostuni E, LeDuc P, Naruse K, Ingber DE and Whitesides GM, Nature 411:1016 (2001).

78 Chen HY, Elkasabi Y and Lahann J, f Am Chem Soc 128:374 (2006). 